\title{
Overexpression of microRNA-130a predicts adverse prognosis of primary gastrointestinal diffuse large B-cell lymphoma
}

\author{
LEIYUAN CHEN ${ }^{1}$, YUTIAN KAN ${ }^{1}$, XINYUAN WANG $^{1}$, PENG GE $^{2}$, TINGTING DING ${ }^{3}$, QIONGLI ZHAI ${ }^{3}$, \\ YAFEI WANG ${ }^{1}$, YONG YU ${ }^{1}$, XIAOFANG WANG ${ }^{1}$, ZHIGANG ZHAO $^{1}$, HONGLIANG YANG $^{1}$, XIANMING LIU $^{4}$, \\ LANFANG $\mathrm{LI}^{4}$, LIHUA QIU ${ }^{4}$, HUILAI ZHANG ${ }^{4}$, ZHENGZI QIAN ${ }^{4}$ and HAIFENG ZHAO ${ }^{1}$ \\ Departments of ${ }^{1}$ Hematology and Oncology, ${ }^{2}$ Laboratory, ${ }^{3}$ Pathology and ${ }^{4}$ Lymphoma, Key Laboratory of \\ Cancer Prevention and Therapy, National Clinical Research Center for Cancer, Tianjin Medical University \\ Cancer Institute and Hospital, Tianjin Clinical Research Center for Cancer, Tianjin 300060, P.R. China
}

Received December 24, 2019; Accepted June 22, 2020

DOI: $10.3892 / \mathrm{ol} .2020 .11954$

\begin{abstract}
Primary gastrointestinal diffuse large B-cell lymphoma (PGI-DLBCL) is a highly heterogeneous type of non-Hodgkin lymphoma. A number of studies have demonstrated that microRNA-130a (miR-130a) serves a role in the tumorigenesis and prognosis of numerous human tumors. However, to the best of our knowledge, the prognostic significance of miR-130a in PGI-DLBCL remains unknown. The present study explored the association between miR-130a and the clinical outcomes of PGI-DLBCL. Relative miR-130a expression was assessed by reverse transcription-quantitative PCR. Immunohistochemistry was used to detect expression levels of BCL-2,c-MYC,neprilysin,B-cell lymphoma 6 protein, PWWP domain-containing DNA repair factor $3 \mathrm{~A}$ and proliferation marker protein $\mathrm{Ki}-67$. A receiver operating characteristic curve was constructed to analyze the specificity and sensitivity of microRNA levels in the diagnosis of PGI-DLBCL. Survival curves were constructed using the Kaplan-Meier method. In the present study, miR-130a expression was notably higher in patients with PGI-DLBCL compared with in the controls $(\mathrm{P}<0.0001)$. miR-130a overexpression was closely associated with a high International Prognostic Index score (3-5) and drug
\end{abstract}

Correspondence to: Dr Huilai Zhang, Department of Lymphoma, Key Laboratory of Cancer Prevention and Therapy, National Clinical Research Center for Cancer, Tianjin Medical University Cancer Institute and Hospital, Tianjin Clinical Research Center for Cancer, 8 West Huan-Hu Road, Tianjin 300060, P.R. China

E-mail: zhangh11122@126.com

Dr Haifeng Zhao, Department of Hematology and Oncology, Key Laboratory of Cancer Prevention and Therapy, National Clinical Research Center for Cancer, Tianjin Medical University Cancer Institute and Hospital, Tianjin Clinical Research Center for Cancer, 8 West Huan-Hu Road, Ti Yuan Bei, Tianjin 300060, P.R. China E-mail: zhaohaifeng457@163.com

Key words: primary gastrointestinal diffuse large B-cell lymphoma, microRNA-130a, expression, resistance, prognosis resistance $(\mathrm{P}=0.017$ and $\mathrm{P}=0.044$, respectively $)$. No significant difference in other clinical features was observed. Patients with increased expression levels of miR-130a had lower overall survival [hazard ratio (HR), 2.998; 95\% CI, 1.347-6.673; $\mathrm{P}=0.007]$ and progression-free survival (HR, 3.325; 95\% CI, 1.488-7.429; $\mathrm{P}=0.003$ ) compared with patients who had lower expression levels of miR-130a. Furthermore, multivariate Cox regression analysis suggested that miR-130a was a negative prognostic parameter in PGI-DLBCL. Therefore, upregulation of miR-130a could become a potential prognostic marker for PGI-DLBCL. Additionally, further study of these results may have important guiding significance for the prognosis of patients with PGI-DLBCL in the clinical setting.

\section{Introduction}

Gastrointestinal (GI) lymphoma is the most common type of extranodal lymphoma, accounting for $5-20 \%$ of all cases $(1,2)$. Nevertheless, primary GI lymphoma is an uncommon malignancy that constitutes only $1-4 \%$ of GI malignancies (3). Primary GI lymphoma is likely to originate within the whole GI tract; however, the most common site of involvement is the stomach, followed by the small intestine (4). Diffuse large B-cell lymphoma (DLBCL) is the major histopathological subtype of primary GI lymphoma (3). In addition, the incidence of non-Hodgkin's lymphoma (NHL) increased by $\sim 1-2 \%$ annually in the 1990s (5). The clinical manifestations of PGI-DLBCL are not obvious, thus PGI-DLBCL is easily misdiagnosed and can be difficult to detect in the early stages of the disease (6). The precise oncogenesis of PGI-DLBCL remains largely unclear. However, there are associated risk factors. Previous studies have described that Helicobacter pylori (H. pylori), human immunodeficiency virus or Epstein-Barr virus infections, as well as inflammatory bowel disease, celiac disease and autoimmune diseases may be associated with the oncogenesis of PGI-DLBCL $(7,8)$. Additionally, genetic changes also serve a crucial role in the tumorigenesis of PGI-DLBCL. For example, the dysregulation of microRNAs (miRNAs) may participate in the pathogenesis of DLBCL, and some specific miRNAs are likely to serve as oncogenes and these are associated with the prognosis in patients with DLBCL (9). Due to the 
relative rarity of this disease, only a small number of studies have been performed in patients with PGI-DLBCL $(7,10)$. Therefore, disease management in patients with PGI-DLBCL remains a challenge, and progress should be made to investigate the pathogenesis and optimal treatment approaches for PGI-DLBCL.

miRNAs belong to an extensive cluster of short, endogenous and single-stranded noncoding RNAs (18-22 nucleotides long), exerting a major role in post-transcriptional gene expression regulation (11). A previous study has demonstrated that miRNAs have a modulating effect upon diverse biological pathways, including cell proliferation, differentiation, motility, apoptosis and drug resistance (12). According to diverse miRNA targets, miRNAs have been demonstrated to be novel oncogenes or tumor suppressor genes. For example, upregulation of miR-30a-5p was demonstrated to significantly inhibit cell proliferation and migration in breast cancer $(13,14)$. Furthermore, miR-15a and miR-16-1 were frequently downregulated in chronic lymphocytic leukemia (15). The dysregulation of miR-155, miR-210, miR-21 expression has been detected in DLBCL and miR-21 has been revealed to have diagnostic and prognostic potential in patients with DLBCL (16). The aberrant expression of miR-130a, located on human chromosome 11, has been found to participate in cancer pathogenesis and tumor progression (17). Additionally, miR-130a expression seems to vary in different tumors, including a series of solid and hematological malignancies. For instance, miR-130a levels are upregulated in gastric cancer, esophageal carcinoma, adult $\mathrm{T}$ cell leukemia, acute myeloid leukemia and DLBCL, whereas miR-130a levels are downregulated in hepatocellular carcinoma cells and chronic lymphocytic leukemia (18-24). Furthermore, accumulating evidence indicates that aberrant expression of miR-130a has treatment and prognostic potential in DLBCL $(22,25)$. However, to the best of our knowledge, the association between miR-130a expression and clinical outcomes in PGI-DLBCL has not yet been examined. Therefore, focusing on miR-130a may provide novel insights into the diagnosis, treatment and prognosis of PGI-DLBCL. The primary goal of the present study was to investigate the clinical significance of miR-130a expression in patients with PGI-DLBCL.

\section{Materials and methods}

Study subjects. Tumor tissues from 80 patients with PGI-DLBCL were collected through surgical resection or endoscopic biopsy at the Tianjin Medical University Cancer Institute and Hospital (Tianjin, China) between January 2011 and December 2015. During the same time period, reactive lymphoid tissue samples were collected from 20 females and 26 males (median age, 56 years; age range 36-68 years) with the same geographical and ethnic backgrounds to be used as controls. Each tissue sample was frozen in liquid nitrogen and then stored at $-80^{\circ} \mathrm{C}$ until further processing. The entire experiment was approved by Tianjin Medical University Cancer Institute and Hospital Ethics Committee and each individual signed written informed consent for participating in the entire study.

Staging and diagnostic procedures. According to the World Health Organization (WHO) classification system for hematological malignancies (26), each patient had a pathologically confirmed diagnosis of PGI-DLBCL. Cases with stomach perforation and intestinal perforation were excluded from the study. Patients were staged according to the Lugano staging system (27), which was revised from the Ann Arbor staging system for GI non-Hodgkin lymphoma. The staging system consisted of the patients' medical history, B symptoms (fever, night sweats and weight loss), Eastern Cooperative Oncology Group (ECOG) performance status (score 0-1 defined as a good performance status in the present study), a medical examination, barium meal examination or an endoscopy, a biopsy or a gastrectomy, a bone marrow biopsy, blood routine examination, blood biochemical profile, abdominal ultrasound and computed tomography (CT) or positron emission tomography-computed tomography scans of the neck, thorax, abdomen and pelvis. The ECOG score is an indicator of a patient's general health status and tolerance to treatment based on their physical strength. ECOG Physical Fitness rating scale scores patients from $0-5$ points (28). Low levels of hemoglobin were defined as $<120 \mathrm{~g} / 1$ in males and $<110 \mathrm{~g} / \mathrm{l}$ in females and high levels of lactate dehydrogenase (LDH) were defined as $>245 \mathrm{U} / 1$. All patients were grouped according to clinical characteristics, such as age, sex, origin, B symptoms, ECOG performance status, Lugano staging system (27), pathological type, LDH level, International Prognostic Index (IPI) score (score 0-2 defined as low IPI group in the present study) and chemotherapy response. The IPI scores patients according to poor prognostic factors including age $>60$ years, high $\mathrm{LDH}$ level, ECOG $\geq 2$, clinical staging of II or IV and $\geq 2$ extranodal sites (29). The clinical characteristics and histological features of the cohort of patients with PGI-DLBCL are shown in Table I.

Treatment. All patients received two treatment methods, including surgery and chemotherapy. In general, surgery was intended to remove tumor tissues and obtain pathologic tissues. None of the patients received treatment prior to the operation, including chemotherapy, radiotherapy and other treatment. All patients received a standard-dose CHOP regimen [cyclophosphamide $\left(750 \mathrm{mg} / \mathrm{m}^{2}\right.$, day 1$)$; doxorubicin $\left(50 \mathrm{mg} / \mathrm{m}^{2}\right.$, day 1); vincristine (1.4 mg/m² , day 1$)$; and prednisone (100 mg, days 1-5)] or R-CHOP regimen [rituximab $\left(375 \mathrm{mg} / \mathrm{m}^{2}\right.$, day 0$)$; cyclophosphamide $\left(750 \mathrm{mg} / \mathrm{m}^{2}\right.$, day 1$)$; doxorubicin $\left(50 \mathrm{mg} / \mathrm{m}^{2}\right.$, day 1$)$; vincristine $\left(1.4 \mathrm{mg} / \mathrm{m}^{2}\right.$, day 1$)$; and prednisone (100 mg, days $1-5)]$ and these were administered for 6-8 cycles (21 days each). Resistance to R-CHOP regimen was defined as patients who had no response to chemotherapy or disease progression during treatment, or patients who had relapsed after achieving complete or incomplete response within 3 months after completing the treatment (22). Patients who were resistant to chemotherapy continued to receive second-line treatment, including DHAP (dexamethasone, cisplatin and cytarabine); ESHAP (etoposide, methylprednisolone, cisplatin and cytarabine); GemOx (gemcitabine and oxaliplatin); DA-EPOCH (etoposide, doxorubicin, vincristine, cyclophosphamide and prednisone); \pm rituximab. Treatment outcome was assessed according to the International Working Group response criteria (30). At the end of every two cycles of chemotherapy (cycles 2, 4, 6 and 8), the efficacy of the treatment was re-evaluated. In addition, after treatment, regular inspections were conducted every 3 months for the first year, every 6 months for the next year and once a year 
Table I. Clinicopathological features of 80 patients with PGI-DLBCL.

\begin{tabular}{|c|c|}
\hline Characteristics & Number $(\%)$ \\
\hline \multicolumn{2}{|l|}{ Age, years } \\
\hline$\leq 60$ & $45(56.2)$ \\
\hline$>60$ & $35(43.8)$ \\
\hline \multicolumn{2}{|l|}{ Sex } \\
\hline Male & $39(48.8)$ \\
\hline Female & $41(51.2)$ \\
\hline \multicolumn{2}{|l|}{ PGI-DLBCL origin } \\
\hline Stomach & $50(62.5)$ \\
\hline Intestinal & $30(37.5)$ \\
\hline \multicolumn{2}{|l|}{ B symptoms } \\
\hline Positive & $26(32.5)$ \\
\hline Negative & $54(67.5)$ \\
\hline \multicolumn{2}{|c|}{ ECOG performance status } \\
\hline $0-1$ & $58(72.5)$ \\
\hline $2-5$ & $22(27.5)$ \\
\hline \multicolumn{2}{|c|}{ Lugano staging system } \\
\hline I-II & $57(71.3)$ \\
\hline IIE-IV & $23(28.7)$ \\
\hline \multicolumn{2}{|l|}{ Pathological type } \\
\hline Non-GCB & $59(73.8)$ \\
\hline GCB & $21(26.2)$ \\
\hline \multicolumn{2}{|l|}{ LDH levels } \\
\hline Normal & $49(61.2)$ \\
\hline Elevated & $31(38.8)$ \\
\hline \multicolumn{2}{|l|}{ IPI score } \\
\hline $0-2$ & $42(52.5)$ \\
\hline $3-5$ & $38(47.5)$ \\
\hline \multicolumn{2}{|c|}{ Chemotherapy response } \\
\hline Drug sensitivity & $52(65.0)$ \\
\hline Drug resistance & $28(35.0)$ \\
\hline \multicolumn{2}{|c|}{ c-MYC upregulation } \\
\hline Negative & $64(80.0)$ \\
\hline Positive & $16(20.0)$ \\
\hline \multicolumn{2}{|c|}{ BCL-2 upregulation } \\
\hline Negative & $52(65.0)$ \\
\hline Positive & $28(35.0)$ \\
\hline \multicolumn{2}{|c|}{$\mathrm{Ki}-67$ proliferation index, $\%$} \\
\hline$<70$ & $33(41.3)$ \\
\hline$\geq 70$ & $47(58.7)$ \\
\hline
\end{tabular}

ECOG, Eastern Cooperative Oncology Group; GCB, germinal center B-cell-like; IPI, International Prognostic Index; Ki-67, proliferation marker protein Ki-67; LDH, lactate dehydrogenase; PGI-DLBCL, primary gastrointestinal diffuse large B-cell lymphoma.

after five years. These evaluations included routine blood tests with biochemical examination, chest and abdomen CT scan, electrocardiogram and ultrasound examination.
RNA extraction and cDNA preparation. Total RNA (1-2 $\mu \mathrm{g})$ was extracted from tumor and lymphoid tissues with TRIzol reagent (Invitrogen; Thermo Fisher Scientific, Inc.). The concentrations and purity of RNA were confirmed by NanoDrop 2000 (NanoDrop Technologies; Thermo Fisher Scientific, Inc.). Subsequently, reverse transcription reactions were performed at $42^{\circ} \mathrm{C}$ using a PrimeScript 1st Strand cDNA synthesis kit (Takara Bio, Inc.) according to the manufacturer's protocol. The generated cDNA was stored at $-20^{\circ} \mathrm{C}$ until further use.

Reverse transcription-quantitative PCR (RT-qPCR). The generated cDNA was subjected to qPCR amplification with the CM9600 Sequence Detection System (Bio-Rad Laboratories, Inc.) and QuantiTect ${ }^{\mathrm{TM}}$ SYBR Green RT-PCR Master Mix (Applied Biosystems; Thermo Fisher Scientific, Inc.). The cycling conditions for the PCR reaction included an initialization at $96^{\circ} \mathrm{C}$ for $5 \mathrm{~min}$, followed by 38 cycles of $96^{\circ} \mathrm{C}$ for $30 \mathrm{sec}$, and a final extension at $65^{\circ} \mathrm{C}$ for $45 \mathrm{sec}$. All measurements were performed in triplicate. To standardize miR-130a expression, U6 was used as an internal control. Therefore, the average $\mathrm{Cq}$ values of miR-130a minus the average $\mathrm{Cq}$ values of U6 equals the $\Delta \Delta \mathrm{Cq}$ values, and $2^{-\Delta \Delta \mathrm{Cq}}$ indicated the quantitative expression levels of miR-130a (31). The primer sequences used in the present study included: miR-130a forward, 5'-TTGCGATTC TGTTTTGTGCT-3' and reverse, 5'-GTGGGGTCCTCAGTG GG-3'; and U6 forward, 5'-CTCGCTTCGGCAGCAC-3' and reverse, 5'-ACGCTTCACGAATTTGC-3'.

Immunohistochemical (IHC) staining and scoring. For IHC staining, all tissue samples were fixed in $10 \%$ buffered formalin for 24-48 $\mathrm{h}$ at room temperature (RT), embedded in paraffin, and cut into $4-\mu \mathrm{m}$-thick sections. Subsequently, paraffin sections were incubated at $67^{\circ} \mathrm{C}$ in the oven for $2 \mathrm{~h}$, followed by dewaxing in xylene for $10 \mathrm{~min}$ and hydration with graded ethanol (concentration, 100, 95, 80, 70 and 50\%) for $5 \mathrm{~min}$. To block the activity of endogenous peroxidase, $3 \%$ hydrogen peroxide was added to all sections, followed by incubation for 10 min at RT. After washing with PBS, $10 \%$ normal goat serum (Cell Signaling Technology, Inc.) was added for $20 \mathrm{~min}$ at RT as a blocking agent. Then, the slides were incubated with the following antibodies: c-MYC (1:200; cat no. ab51154; Abcam), BCL-2 (1:50; cat no. ZM0010), neprilysin (CD10; 1:100; cat. no. ZM0283;), B-cell lymphoma 6 protein (BCL-6; 1:100; cat. no. ZM-0011), PWWP domain-containing DNA repair factor 3A (MUM1; 1:100; cat. no. ZA-0583) (all purchased from OriGene Technologies, Inc.) and proliferation marker protein Ki-67 (1:100; cat. no. 12202, Cell Signaling Technology, Inc.) at $4^{\circ} \mathrm{C}$ overnight. After washing with PBS, the secondary antibodies (100 $\mu \mathrm{l}$ neat; cat. no. PV-6000; OriGene Technologies, Inc.) were applied to the samples for $20 \mathrm{~min}$ at $37^{\circ} \mathrm{C}$. Following this, diaminobenzidine was used for staining, and cell nuclei were counterstained with hematoxylin for $5 \mathrm{~min}$ at RT. The results were identified as positive when $\sim 30 \%$ or more of the sample was stained. The slice was observed under a light microscope (magnification, x200) and the results were obtained with the Image Pro Plus image analysis software version 7.0 (Meyer Instruments, Inc.). All cases were divided, based on the algorithms of Muris et al (32) and Hans et al (33), into germinal center B-cell-like (GCB) and non-GCB phenotype. 


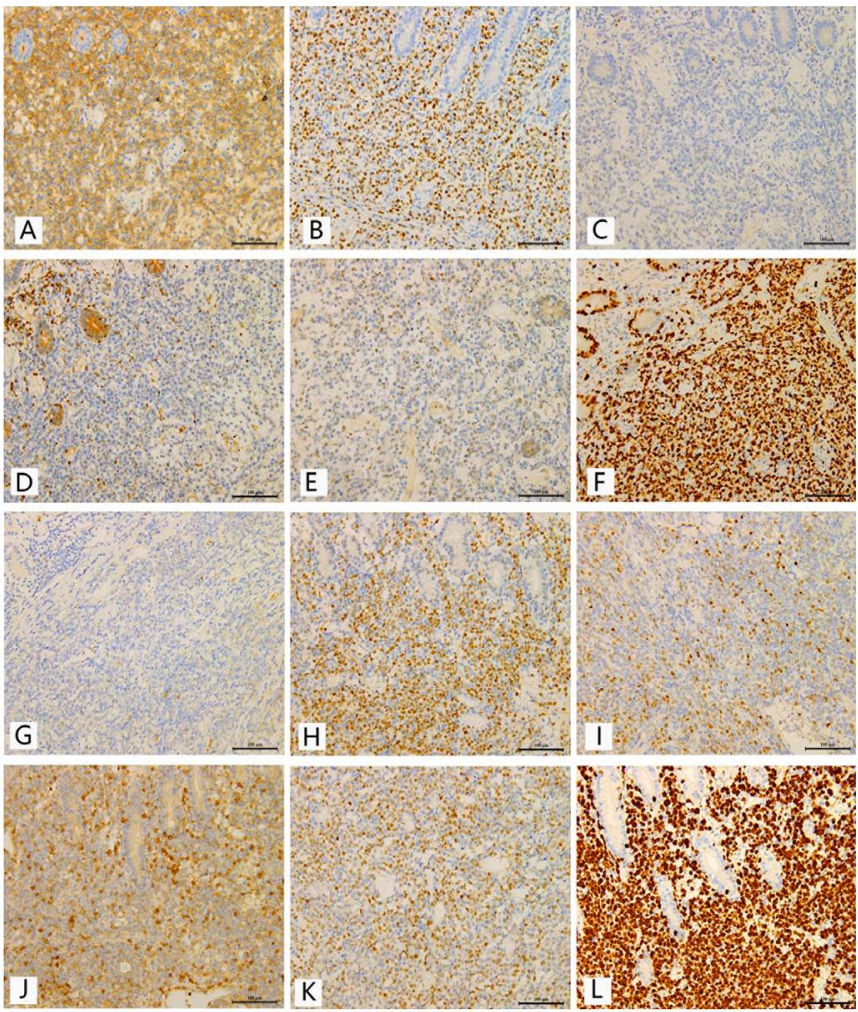

Figure 1. Representative immunohistochemical analyses of CD10, BCL-6, MUM-1, BCL-2, c-MYC and Ki-67 in samples from patients with primary gastrointestinal diffuse large B-cell lymphoma. Scale bar, $100 \mu \mathrm{m}$. Immunostaining for (A) CD10, (B) BCL-6, (C) MUM-1, (D) BCL-2, (E) c-MYC and (F) Ki-67 in the GCB subgroup. Immunostaining for (G) CD10, (H) BCL-6, (I) MUM-1, (J) BCL-2, (K) c-MYC and (L) Ki-67 in the non-GCB subgroup. GCB, germinal center B-cell like; BCL-6, B-cell lymphoma 6; MUM-1, multiple myeloma antigen 1; BCL-2, B-cell lymphoma 2.

The staining intensity and the percentage of positive cells were recorded. Staining intensity was scored as follows: 0 , no staining; $1+,>25 \%$ of the tumor cells exhibited weak staining; $2+$, tumor cells exhibited moderate staining; and 3+, tumor cells exhibited strong staining (Fig. 1).

Statistical analysis. Each sample was run in triplicate. All statistical calculations were performed with the IBM SPSS Statistics software (version 20.0; IBM Corp.). The GraphPad Prism software package (version 6.01; GraphPad Software, Inc.) was used to generate all presented graphics. Data were presented as mean \pm SD. The miR-130a levels in patients with PGI-DLBCL and control individuals were analyzed using the non-parametric Mann-Whitney U test. Group comparisons were made using the $\chi^{2}$ test. Receiver operating characteristic (ROC) curves and the area under the ROC curve (AUC) were determined to evaluate the feasibility of using miRNA levels for the diagnosis of PGI-DLBCL. The survival curve was constructed by Kaplan-Meier analysis and log-rank tests were used to analyze the differences in survival curves. Overall survival (OS) referred to the period from the date of diagnosis until death or final follow-up (in March 2019). Progression-free survival (PFS) referred to the time between the date of diagnosis and the observation of treatment failure, clinical recurrence of the disease, death or last follow-up. Significant parameters identified in univariate analysis $(\mathrm{P}<0.05)$ were incorporated
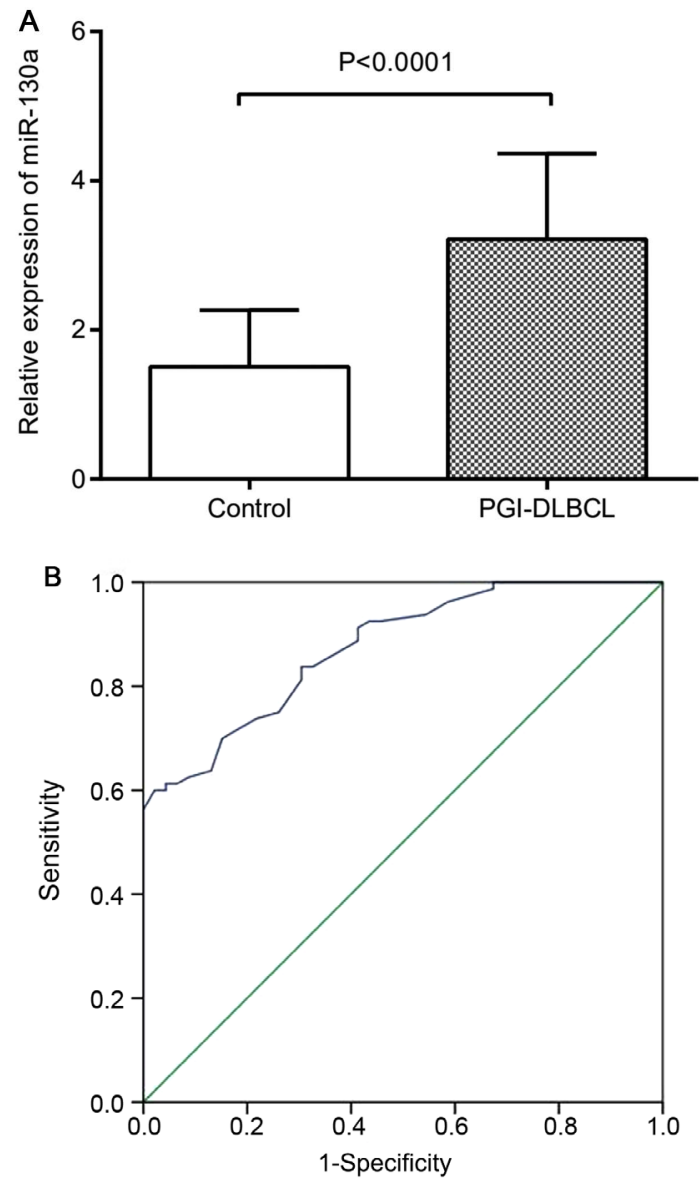

Figure 2. miR-130a expression and diagnostic significance in the tissues of patients with PGI-DLBCL and healthy controls. (A) Expression levels of miR-130a were analyzed by reverse transcription-quantitative PCR analysis. miR-130a expression in cancer tissues of patients with PGI-DLBCL was notably higher than that in controls $(\mathrm{P}<0.0001)$. (B) Receiver operating characteristic curve analysis of miR-130a expression to discriminate between tissue specimens from patients with PGI-DLBCL and healthy controls. The area under the curve was 0.874 with a sensitivity of $60 \%$ and a specificity of $78 \%$, suggesting a potential diagnostic value of miR-130a in PGI-DLBCL (95\% CI, 0.816-0.932; $\mathrm{P}=0.030$ ). miR, microRNA; PGI-DLBCL, primary gastrointestinal diffuse large $\mathrm{B}$ cell lymphoma.

into multivariate Cox regression analysis to determine independent prognostic factors. The minimal sample size was estimated by PASS. An AUC value of miR-130a in DLBCL reported in a prior study was $\sim 0.7$ (22). The minimal sample size was calculated with an AUC0 value of 0.5 , AUC1 of 0.7 and a case/control ratio of 1 . $\mathrm{P}<0.05$ was considered to indicate a statistically significant difference.

\section{Results}

Clinical characteristics and immunophenotypic features in PGI-DLBCL. A total of 80 patients, including 39 men and 41 women with a median age of 53 years, and 46 healthy subjects were recruited in the present study. The majority of patients (56.2\%) were $\leq 60$ years old, 31 patients (38.8\%) presented with elevated LDH levels and 26 patients (32.5\%) exhibited positive B symptoms. According to Zubrod-ECOG-WHO (namely ECOG score) and the Lugano staging system, 58 patients $(72.5 \%)$ presented a good performance status $(0-1)$, whereas 23 patients $(28.7 \%)$ presented with stage IIE/IV (advanced 
Table II. Association between clinical characteristics and miR-130a expression in patients with PGI-DLBCL.

\begin{tabular}{|c|c|c|c|c|}
\hline \multirow[b]{2}{*}{ Characteristics } & \multirow[b]{2}{*}{ No. of patients (\%) } & \multicolumn{2}{|c|}{ miR-130a expression levels, $\mathrm{n}$} & \multirow[b]{2}{*}{ P-value } \\
\hline & & Low $(n=32)$ & High $(n=48)$ & \\
\hline \multicolumn{5}{|l|}{ Age, years } \\
\hline$\leq 60$ & $45(56.2)$ & 20 & 25 & \multirow[t]{2}{*}{0.358} \\
\hline$>60$ & $35(43.8)$ & 12 & 23 & \\
\hline \multicolumn{5}{|l|}{ Sex } \\
\hline Male & $39(48.8)$ & 14 & 25 & \multirow[t]{2}{*}{0.465} \\
\hline Female & $41(51.2)$ & 18 & 23 & \\
\hline \multicolumn{5}{|l|}{ PGIDLBCL origin } \\
\hline Stomach & $50(62.5)$ & 21 & 29 & \multirow[t]{2}{*}{0.637} \\
\hline Intestinal & $30(37.5)$ & 11 & 19 & \\
\hline \multicolumn{5}{|l|}{ B symptoms } \\
\hline Positive & $26(32.5)$ & 9 & 17 & \multirow[t]{2}{*}{0.495} \\
\hline Negative & $54(67.5)$ & 23 & 31 & \\
\hline \multicolumn{5}{|c|}{ ECOG performance status } \\
\hline $0-1$ & $58(72.5)$ & 21 & 37 & \multirow[t]{2}{*}{0.261} \\
\hline $2-5$ & $22(27.5)$ & 11 & 11 & \\
\hline \multicolumn{5}{|c|}{ Lugano staging system } \\
\hline I-II & $57(71.3)$ & 21 & 36 & \multirow[t]{2}{*}{0.364} \\
\hline IIE-IV & $23(28.7)$ & 11 & 12 & \\
\hline \multicolumn{5}{|l|}{ Pathological type } \\
\hline Non-GCB & $59(73.8)$ & 21 & 38 & \multirow[t]{2}{*}{0.177} \\
\hline GCB & $21(26.2)$ & 11 & 10 & \\
\hline \multicolumn{5}{|l|}{ LDH } \\
\hline Normal & $49(61.2)$ & 23 & 26 & \multirow[t]{2}{*}{0.111} \\
\hline Elevated & $31(38.8)$ & 9 & 22 & \\
\hline \multicolumn{5}{|l|}{ IPI score } \\
\hline $0-2$ & $42(52.5)$ & 22 & 20 & \multirow[t]{2}{*}{0.017} \\
\hline $3-5$ & $38(47.5)$ & 10 & 28 & \\
\hline \multicolumn{5}{|c|}{ Chemotherapy response } \\
\hline Drug sensitivity & $52(65.0)$ & 25 & 27 & \multirow[t]{2}{*}{0.044} \\
\hline Drug resistance & $28(35.0)$ & 7 & 21 & \\
\hline
\end{tabular}

ECOG, Eastern Cooperative Oncology Group; GCB, germinal center B-cell-like; IPI, International Prognostic Index; LDH, lactate dehydrogenase; miR-130a, microRNA-130a; PGI-DLBCL, primary gastrointestinal diffuse large B-cell lymphoma.

stage) PGI-DLBCL at the time of diagnosis. BCL-6, CD10 and MUM1 staining were performed for all cases, and 21 patients (26.2\%) were confirmed with GCB, and 59 patients $(73.8 \%$ ) with non-GCB. Additionally, low IPI scores (0-2) were identified in 42 patients $(52.5 \%)$, and chemotherapy drug resistance was observed in 28 patients $(35.0 \%)$. Table I summarizes the baseline clinicopathological features of patients with PGI-DLBCL.

To examine the difference in miR-130a expression between the case group and the control group, the recruited 80 patients and 46 controls were used to perform a case-control study. The results demonstrated that the expression levels of miR-130a in tumor tissues from patients with PGI-DLBCL were markedly increased compared with those of the controls (Fig. 2A). ROC curves were used to evaluate the sensitivity and specificity of miR-130a expression levels in discriminating between normal and tumor tissues. When the optimal cut-off value of miR-130a was 3.21 and the AUC was 0.874 , the optimum sensitivity and specificity were obtained (60 and 78\%, respectively) in the present study (Fig. 2B). According to this cut-off value, 32 patients were included in the low-miR-130a expression group (expression $\mathrm{Cq}$ value $<3.21$ ) and 48 patients were included in the high-miR-130a expression group (expression Cq value $\geq 3.21$ ).

Association between miR-130a expression and the clinical features of PGI-DLBCL. Clinical information of patients with PGI-DLBCL, including age, sex, origin, B symptoms, ECOG score, staging, pathological type, LDH level, IPI score and chemotherapy response, was collected. Increased levels of miR-130a were closely associated with high IPI score $(\mathrm{P}=0.01$; Table II) and drug resistance $(\mathrm{P}=0.044$; Table II), indicating the 

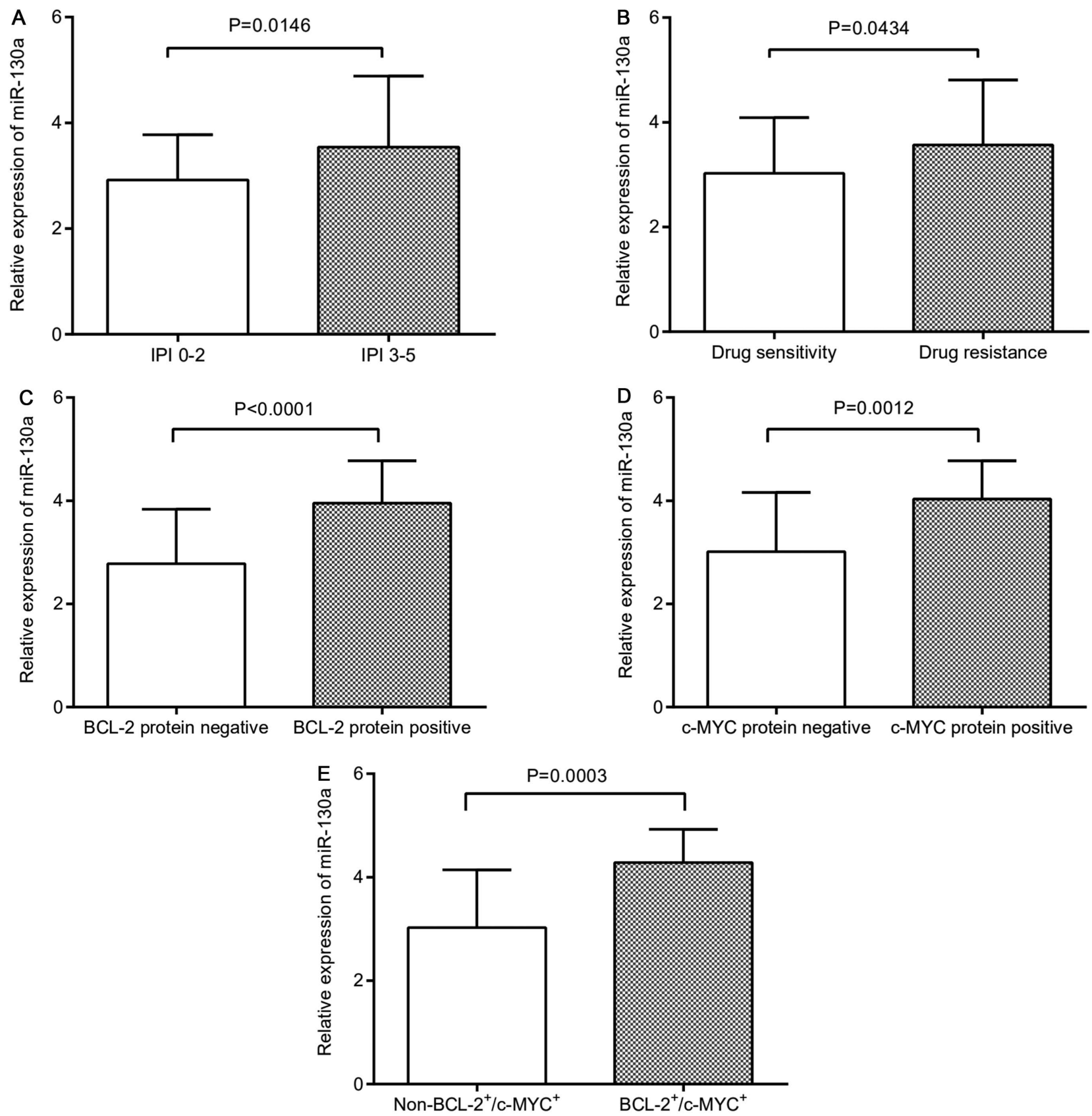

Figure 3. Relative miR-130a expression is associated with clinicopathological features in patients with PGI-DLBCL. miR-130a was significantly increased in the (A) high IPI subgroup, (B) drug resistance subgroup, (C) BCL-2 protein positive subgroup, (D) c-MYC protein positive subgroup and (E) and BCL-2 $/$ $\mathrm{c}^{-\mathrm{MYC}^{+}}$subgroup in the entire cohort of patients with PGI-DLBCL $(\mathrm{n}=80)$. IPI, International Prognostic Index; miR, microRNA; PGI-DLBCL, primary gastrointestinal diffuse large B cell lymphoma.

difference was statistically significant. Nevertheless, no statistical differences were observed in other subgroups based on age, sex, origin, B symptoms, ECOG score, staging, pathological type and LDH level in patients with PGI-DLBCL, between the high and low expression of miR-139a groups. When investigating the association between the expression levels of miR-130a and high IPI score (3-5) and drug resistance, the relative expression of miR-130a was found to be significantly higher in IPI score (3-5) and drug resistance groups compared with their respective controls, IPI score (0-2) and drug sensitivity (Fig. 3A and B).

IHC findings. As shown in Table III, there were 28 cases (35.0\%) with BCL-2 positive staining, 16 cases $(20.0 \%)$ with c-MYC overexpression and 47 cases (58.7\%) with high $\mathrm{Ki}-67$ positive staining. The co-expression of BCL-2 and c-MYC proteins in DLBCL is known as 'double-expression' lymphoma $(34,35)$, and this was observed in 12 patients in the present study. Additionally, the overexpression of BCL-2 and c-MYC were associated with increased expression levels of miR-130a (Fig. 3C and D), and co-expression of BCL-2 and c-MYC showed a significant association with higher miR-130a levels (Fig. 3E).

Survival and prognostic analysis. Upregulation of miR-130a was associated with shorter OS rate and PFS rate in patients with PGI-DLBCL (Fig. 4A and B). As shown in Table IV, the univariate analysis suggested overexpression of miR-130a 
Table III. Association between IHC markers and miR-130a expression in primary gastrointestinal diffuse large B-cell lymphoma.

miR-130a expression levels

\begin{tabular}{|c|c|c|c|c|}
\hline \multirow[b]{2}{*}{ IHC markers } & \multirow[b]{2}{*}{ No. of patients (\%) } & & \multirow[b]{2}{*}{$\mathrm{P}$-value } \\
\hline & & Low $(n=32)$ & High $(n=48)$ & \\
\hline \multicolumn{5}{|c|}{ c-MYC upregulation } \\
\hline Negative & $64(80.0)$ & 30 & 34 & 0.012 \\
\hline Positive & $16(20.0)$ & 2 & 14 & \\
\hline \multicolumn{5}{|c|}{ BCL-2 upregulation } \\
\hline Negative & $52(65.0)$ & 28 & 24 & 0.001 \\
\hline Positive & $28(35.0)$ & 4 & 24 & \\
\hline \multicolumn{5}{|c|}{ Ki-67 proliferation index } \\
\hline$<70 \%$ & $33(41.3)$ & 17 & 16 & 0.078 \\
\hline$\geq 70 \%$ & $47(58.7)$ & 15 & 32 & \\
\hline
\end{tabular}

IHC, immunohistochemical; Ki-67, proliferation marker protein Ki-67; miR-130a, microRNA-130a.

Table IV. Univariate analysis of the significance of different prognostic variables for primary gastrointestinal diffuse large B cell lymphoma.

\begin{tabular}{|c|c|c|c|c|}
\hline \multirow[b]{2}{*}{ Variables } & \multicolumn{2}{|c|}{ Overall survival } & \multicolumn{2}{|c|}{ Progression-free survival } \\
\hline & HR $(95 \%$ CI $)$ & P-value & $\mathrm{HR}(95 \% \mathrm{CI})$ & P-value \\
\hline Age $(\leq 60$ vs. $>60$ years $)$ & $1.110(0.521-2.362)$ & 0.787 & $1.030(0.483-2.196)$ & 0.940 \\
\hline Sex (male vs. female) & $0.847(0.406-1.769)$ & 0.659 & $0.770(0.369-1.606)$ & 0.485 \\
\hline Origin (stomach vs. intestinal) & $1.555(0.746-3.243)$ & 0.239 & $1.605(0.772-3.334)$ & 0.205 \\
\hline B symptoms (positive vs. negative) & $0.704(0.311-1.593)$ & 0.400 & $0.733(0.324-1.659)$ & 0.455 \\
\hline ECOG (0-1 vs. $2-4)$ & $1.569(0.747-3.299)$ & 0.234 & $1.630(0.773-3.440)$ & 0.199 \\
\hline Lugano stage (I-II vs. IIE-IV) & $0.877(0.386-1.994)$ & 0.754 & $0.854(0.376-1.936)$ & 0.705 \\
\hline Pathological type (non-GCB vs. GCB) & $0.588(0.249-1.391)$ & 0.227 & $0.657(0.279-1.548)$ & 0.337 \\
\hline LDH (normal vs. elevated) & $1.835(0.884-3.810)$ & 0.103 & $1.983(0.954-4.123)$ & 0.067 \\
\hline IPI (0-2 vs. $3-5)$ & $2.170(1.034-4.551)$ & 0.040 & $2.231(1.059-4.701)$ & 0.035 \\
\hline Chemotherapy response (drug sensitivity vs. drug resistance) & $0.719(0.317-1.631)$ & 0.430 & $0.830(0.367-1.878)$ & 0.654 \\
\hline c-MYC (positive vs. negative) & $1.469(0.552-3.904)$ & 0.441 & $1.793(0.659-4.876)$ & 0.253 \\
\hline BCL-2 (positive vs. negative) & $1.289(0.607-2.740)$ & 0.509 & $1.461(0.687-3.108)$ & 0.324 \\
\hline BCL-2/c-MYC co-expression (BCL-2 $/ \mathrm{c}-\mathrm{MYC}^{+}$vs. others) & $1.111(0.449-2.751)$ & 0.820 & $1.218(0.494-3.001)$ & 0.669 \\
\hline Ki-67 index (<70 vs. $\geq 70 \%)$ & $1.398(0.659-2.966)$ & 0.383 & $1.346(0.635-2.854)$ & 0.439 \\
\hline miR-130a expression (low vs. high) & $2.998(1.347-6.673)$ & 0.007 & $3.325(1.488-7.429)$ & 0.003 \\
\hline
\end{tabular}

ECOG, Eastern Cooperative Oncology Group; GCB, germinal center B-cell-like; HR, hazard ratio; IPI, International Prognostic Index; LDH, lactate dehydrogenase; miR-130a, microRNA-130a; others, including BCL-2 $/ \mathrm{c}-\mathrm{MYC}^{-}, \mathrm{BCL}^{-2} / \mathrm{c}-\mathrm{MYC}^{+}$and $\mathrm{BCL}^{-2} / \mathrm{c}-\mathrm{MYC}^{-}$.

and high IPI score were associated with unfavorable patient outcomes. All other analyzed parameters exhibited no prognostic significance. Multivariate survival analysis indicated that miR-130a expression was an independent negative prognostic factor in PGI-DLBCL (Table V).

\section{Discussion}

Primary GI lymphoma is a malignant tumor which gradually infiltrates the alimentary tract. The IPI score is used to predict the prognosis of patients with DLBCL aggressive lymphoma and includes five clinical parameters (age, ECOG score, clinical staging, LDH levels and the number of sites of extranodal invasion) (7). However, the IPI evaluation system only contains some clinical features, dismissing the molecular biology of cancer. Therefore, novel biomarkers should be explored to improve the assessment of the prognosis of PGI-DLBCL. Increasing evidence indicates that miRNAs are closely associated with the pathogenesis and prognostic significance of diverse types of cancer, including DLBCL. For example, miR-155 is overexpressed in DLBCL cells and has emerged as a negative prognostic marker (36). In addition, 
Table V. Multivariate analysis of the significance of independent prognostic variables for primary gastrointestinal diffuse large B cell lymphoma.

\begin{tabular}{lcccccr}
\hline \multirow{2}{*}{ Variables } & \multicolumn{2}{c}{ Overall survival } & & \multicolumn{2}{c}{ Progression-free survival } \\
\cline { 2 - 3 } & HR $(95 \%$ CI $)$ & P-value & & HR (95\% CI $)$ & P-value \\
\hline IPI (0-2 vs. 3-5) & $1.479(0.654-3.342)$ & 0.347 & & $1.379(0.596-3.188)$ & 0.453 \\
miR-130a expression (low vs. high) & $2.516(1.046-6.052)$ & & 0.039 & & $2.828(1.143-6.994)$ & 0.024 \\
\hline
\end{tabular}

HR, hazard ratio; IPI, International Prognostic Index; miR-130a, microRNA-130a.
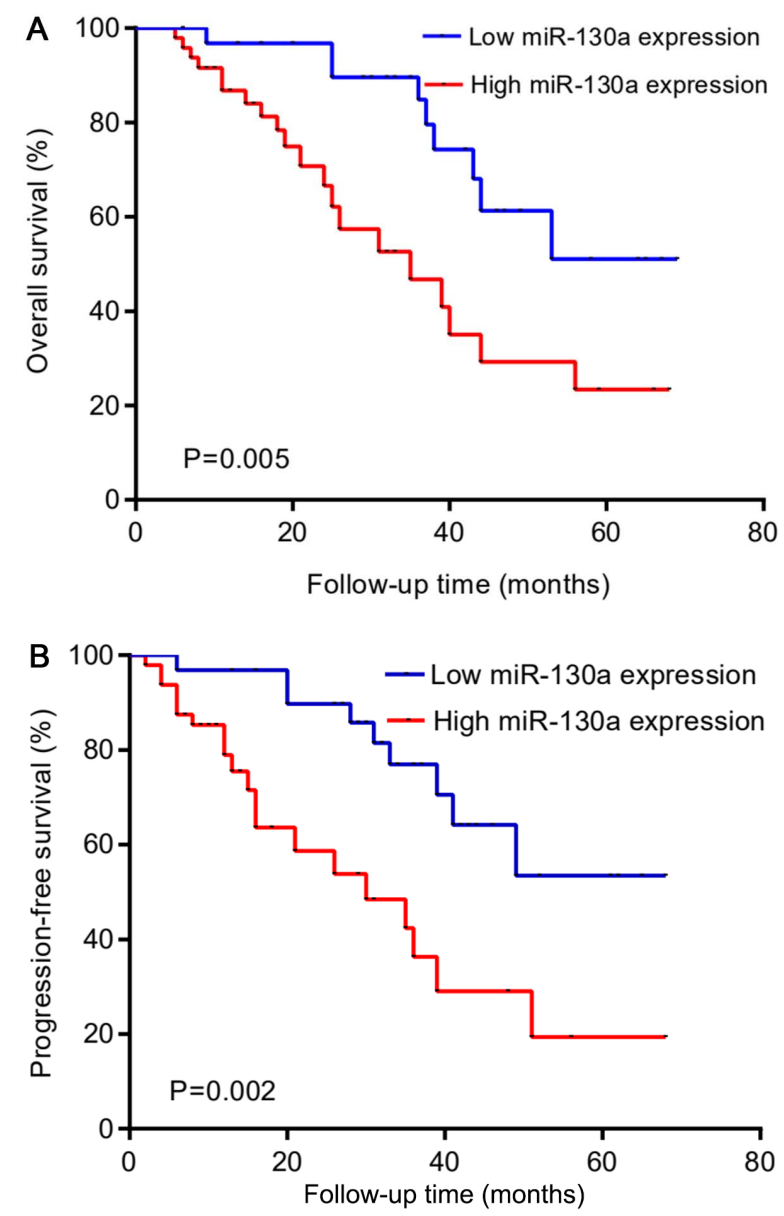

Figure 4. Upregulation of miR-130a is associated with poor prognosis in patients with primary gastrointestinal diffuse large B cell lymphoma. (A) Overall survival and (B) progression-free survival times in the high miR-130a expression subgroup were shorter than those in the low miR-130a expression subgroup. miR, microRNA.

reduced miR-34a expression in DLBCL acts as a tumor suppressor (37,38). Interestingly, previous studies have demonstrated that miR-130a serves a vital role in the tumorigenesis of numerous hematological malignancies, including chronic lymphocytic leukemia (24), acute myeloid leukemia (21) and adult $\mathrm{T}$ cell leukemia (20). However, miR-130a expression in PGI-DLBCL still requires further research.

In the present study, miR-130a expression in the tumor tissues from patients with PGI-DLBCL and control subjects was evaluated by RT-qPCR. The results revealed significantly higher miR-130a expression in PGI-DLBCL tissues compared with the control tissues, suggesting that miR-130a may be a potential diagnostic factor of PGI-DLBCL. In addition, the data indicated that miR-130a expression was associated with high IPI score and chemotherapy resistance. Several studies have indicated that miR-130a has a modulating effect on chemotherapy drug resistance in diverse types of cancer, including ovarian cancer (39), lung cancer (40), liver cancer (41) and DLBCL (42). Furthermore, Yuan et al (22) reported that higher levels of miR-130a and miR-125b in patients with DLBCL treated with R-CHOP had an adverse effect on disease remission and chemosensitivity. Similar results have been reported in other cancer types, including hematologic malignancies, where miR-130a has the potential to regulate drug susceptibility by activating the $\mathrm{Wnt} / \beta$-catenin and PI3K/AKT/mTOR signaling pathways $(17,41,42)$. As aforementioned, in the present study, miR-130a was likely to be associated with chemotherapy drug resistance in PGI-DLBCL. However, the potential mechanism remains to be elucidated, as there was no adequate evidence showing that miR-130a induces drug resistance by activating a particular signaling pathway in PGI-DLBCL.

BCL-2 and c-MYC serve crucial roles in the pathogenesis of DLBCL $(43,44)$. The constitutive activity of NF- $\kappa$ B results in the upregulation of numerous NF- $\mathrm{KB}$ target genes, including MYC and BCL-2 $(45,46)$. Furthermore, some miRNAs may have an effect on NF- $\mathrm{kB}$ expression, whereas NF- $\kappa B$ can transcriptionally modulate miR-130a expression $(47,48)$. In addition, the elevated expression of c-MYC might control miR-130a upregulation, which could be regulated by product c-MYC (namely the c-MYC protein encoded by exons 2 and 3), forming complex regulatory loops (49-51). In the present study, data demonstrated that BCL-2 positive and c-MYC positive were associated with high expression levels of miR-130a, which, considering the aforementioned observations, suggests that miR-130a might be involved in regulating BCL-2 and c-MYC expression. Previous studies have reported that patients with $\mathrm{BCL}-2^{+}, \mathrm{c}-\mathrm{MYC}^{+}$or $\mathrm{BCL}-2^{+} /$ $\mathrm{c}-\mathrm{MYC}^{+}$have a worse prognosis compared with patients with BCL-2- c-MYC ${ }^{-}$or others (including $\mathrm{BCL}-2^{-} / \mathrm{c}-\mathrm{MYC}^{+}$, $\mathrm{BCL}^{+} / \mathrm{c}-\mathrm{MYC}^{-}$and BCL$\left.-2 / \mathrm{c}-\mathrm{MYC}\right)$ in patients with DLBCL or PGI-DLBCL $(7,34,43,45,52)$. However, in the present study, data suggested that BCL-2 and c-MYC expression or co-expression of both, along with high Ki-67 index were not associated with prognosis in PGI-DLBCL. Therefore, additional investigations are required to elucidate the association between BCL-2, c-MYC and their co-expression and the prognosis of patients with PGI-DLBCL. 
The association between miR-130a expression and the prognosis of various types of cancer has been investigated. Increased miR-130a expression in gastric cancer is associated with inferior OS (53), and increased miR-130a expression in non-small cell lung cancer is associated with an unfavorable prognosis (54). In the present study, patients with high miR-130a levels had poor outcomes compared with those with low miR-130a levels. Additionally, multivariate analyses adjusting for known factors indicated that miR-130a was an independent prognostic factor for OS and PFS rates. This result is consistent with a previous study where miR-130a and miR-125b were identified as potential novel biomarkers for assessing treatment response and predicting survival of patients with DLBCL (22). Nevertheless, the mechanism of the potential relationship between increased miR-130a expression and poor prognosis remains unclear. However, previous studies have revealed that aberrant miR-130a expression increases DNA methylation resulting in promoter silencing, and the overexpression of DNA methyltransferase 1 is associated with adverse prognosis in patients with PGI-DLBCL $(24,55,56)$. Overall, these results indicated that miR-130a overexpression could be a promising predictor of poor prognosis for PGI-DLBCL. In the future, miR-130a expression might become a useful clinical tool to predict patient survival and guide therapeutic strategies.

There are a number of limitations to the present study. Firstly, there was a limited number of samples used, which is partly due to the relative rarity of PGI-DLBCL. However, the minimal sample size computed by PASS software was 41 patients and 41 controls, which indicated that the used sample size in the present study was suitable for preliminary exploration. In addition, the present findings may provide a basis for further experiments to validate the expression and role of miR-130a in a larger cohort of patients with PGI-DLBCL. Secondly, the association between drug resistance and the overexpression of miR-130a only showed a significance of 0.044 . However, there is evidence showing that miR-130a has an impact on the resistance to chemotherapeutic drugs in various types of cancer, including DLBCL (22). Therefore, the low significance described in the present study might be partially attributed to the relatively limited sample size. Therefore, larger sample size studies are required to validate the results. Finally, miR-130a expression levels were assessed by RT-qPCR which is a relative quantification approach with reduced accuracy compared with digital PCR $(57,58)$ which is an absolute quantitative technique for nucleic acids. Therefore, digital PCR may be more adequate for further studies and validation of the present findings.

In conclusion, the present data suggest that miR-130a levels can distinguish patients with PGI-DLBCL from healthy individuals, which might be a potential diagnostic marker for PGI-DLBCL. Furthermore, high miR-130a expression may represent a potential novel biomarker for the prognosis of PGI-DLBCL. This finding might be used in daily clinical work and provide novel therapeutic options for patients with PGI-DLBCL.

\section{Acknowledgements}

Not applicable.

\section{Funding}

The present study was financially supported by The National Natural Science Foundation of China (grant nos. 81100337 and 81470283).

\section{Availability of data and materials}

The datasets used and/or analyzed during the current study are available from the corresponding author on reasonable request.

\section{Authors' contributions}

LC performed the experiments, analyzed the data and wrote the paper. YK and XYW performed the experiments. PG, TD and QZ contributed to patient sample collection and literature retrieval. YW, YY, XFW, ZZ, HY, XL, LL and LQ participated in gathering clinical information and acquisition of data. HYZ conceived the experiments and acquired the funding. LC, ZZQ, HLZ and HFZ designed the experiments and supervised the study. All authors read and approved the final manuscript.

\section{Ethics approval and consent to participate}

The present study was approved by Tianjin Medical University Cancer Institute and Hospital Ethics Committee. Written informed consent was obtained from each patient included in the present study.

\section{Patient consent for publication}

Not applicable.

\section{Competing interests}

The authors declare that they have no competing interests.

\section{References}

1. Freeman C, Berg JW and Cutler SJ: Occurrence and prognosis of extranodal lymphomas. Cancer 29: 252-260, 1972.

2. Berglund M, Hedström G, Amini RM,Enblad G and Thunberg U: High expression of microRNA-200c predicts poor clinical outcome in diffuse large B-cell lymphoma. Oncol Rep 29: 720-724, 2013.

3. Papaxoinis G, Papageorgiou S, Rontogianni D, Kaloutsi V, Fountzilas G, Pavlidis N, Dimopoulos M, Tsatalas C, Xiros N and Economopoulos T: Primary gastrointestinal non-Hodgkin's lymphoma: A clinicopathologic study of 128 cases in Greece. A Hellenic Cooperative Oncology Group study (HeCOG). Leuk Lymphoma 47: 2140-2146, 2006.

4. Herrmann R, Panahon AM, Barcos MP, Walsh D and Stutzman L: Gastrointestinal involvement in non-Hodgkin's lymphoma. Cancer 46: 215-222, 1980.

5. Müller AM, Ihorst G, Mertelsmann R and Engelhardt $M$ : Epidemiology of non-Hodgkin's lymphoma (NHL): Trends, geographic distribution, and etiology. Ann Hematol 84: 1-12, 2005.

6. Malipatel R, Patil M, Pritilata Rout P, Correa M and Devarbhavi H: Primary gastric lymphoma: Clinicopathological profile. Euroasian J Hepatogastroenterol 8: 6-10, 2018.

7. Xia B, Zhang L, Guo SQ, Li XW, Qu FL, Zhao HF, Zhang LY, Sun BC, You J and Zhang YZ: Coexpression of MYC and BCL-2 predicts prognosis in primary gastrointestinal diffuse large B-cell lymphoma. World J Gastroenterol 21: 2433-2442, 2015.

8. Peng JC, Zhong L and Ran ZH: Primary lymphomas in the gastrointestinal tract. J Dig Dis 16: 169-176, 2015. 
9. Esquela-Kerscher A and Slack FJ: Oncomirs-microRNAs with a role in cancer. Nat Rev Cancer 6: 259-269, 2006.

10. Zhao H, Zhang L, Guo S, Yuan T, Xia B, Qu F, Zhang L and Zhang Y: Downregulated expression of Dicerl predicts inferior survival in primary gastrointestinal diffuse large B-cell lymphoma treated with CHOP-like regimen and rituximab. Med Oncol 31: 206, 2014.

11. Treiber T, Treiber $\mathrm{N}$ and Meister G: Regulation of microRNA biogenesis and function. Thromb Haemost 107: 605-610, 2012.

12. Chen X, Lu P, Wang DD, Yang SJ, Wu Y, Shen HY, Zhong SL, Zhao JH and Tang JH: The role of miRNAs in drug resistance and prognosis of breast cancer formalin-fixed paraffin-embedded tissues. Gene 595: 221-226, 2016.

13. Wang D, Qiu C, Zhang H, Wang J, Cui Q and Yin Y: Human microRNA oncogenes and tumor suppressors show significantly different biological patterns: from functions to targets. PLoS One 5: e13067, 2010.

14. Xiong J, Wei B, Ye Q and Liu W: MiR-30a-5p/UBE3C axis regulates breast cancer cell proliferation and migration. Biochem Biophys Res Commun 516: 1013-1018, 2016.

15. Calin GA, Ferracin M, Cimmino A, Di Leva G, Shimizu M, Wojcik SE, Iorio MV, Visone R, Sever NI, Fabbri M, et al: A MicroRNA signature associated with prognosis and progression in chronic lymphocytic leukemia. N Engl J Med 353: 1793-1801, 2005

16. Lawrie $\mathrm{CH}$, Gal S, Dunlop HM, Pushkaran B, Liggins AP, Pulford K, Banham AH, Pezzella F, Boultwood J, Wainscoat JS, et al: Detection of elevated levels of tumour-associated microRNAs in serum of patients with diffuse large B-cell lymphoma. Br J Haematol 141: 672-675, 2008

17. Zhang HD, Jiang LH, Sun DW, Li J and Ji ZL: The role of miR-130a in cancer. Breast Cancer 24: 521-527, 2017.

18. Jiang H, Yu WW, Wang LL and Peng Y: miR-130a acts as a potential diagnostic biomarker and promotes gastric cancer migration, invasion and proliferation by targeting RUNX3. Oncol Rep 34: $1153-1161,2015$

19. Liu SG, Qin XG, Zhao BS, Qi B, Yao WJ, Wang TY, Li HC and Wu XN: Differential expression of miRNAs in esophageal cancer tissue. Oncol Lett 5: 1639-1642, 2013.

20. Ishihara K, Sasaki D, Tsuruda K, Inokuchi N, Nagai K Hasegawa H, Yanagihara K and Kamihira S: Impact of miR-155 and miR-126 as novel biomarkers on the assessment of disease progression and prognosis in adult T-cell leukemia. Cancer Epidemiol 36: 560-565, 2012

21. Ding C, Chen SN, Macleod RAF, Drexler HG, Nagel S, Wu DP, Sun AN and Dai HP: MiR-130a is aberrantly overexpressed in adult acute myeloid leukemia with $\mathrm{t}(8 ; 21)$ and its suppression induces AML cell death. Ups J Med Sci 123: 19-27, 2018

22. Yuan WX, Gui YX, Na WN, Chao J and Yang X: Circulating microRNA-125b and microRNA-130a expression profiles predict chemoresistance to R-CHOP in diffuse large B-cell lymphoma patients. Oncol Lett 11: 423-432, 2016.

23. Li B, Huang P, Qiu J, Liao Y, Hong J and Yuan Y: MicroRNA-130a is down-regulated in hepatocellular carcinoma and associates with poor prognosis. Med Oncol 31: 230, 2014.

24. Kovaleva V, Mora R, Park YJ, Plass C, Chiramel AI, Bartenschlager R, Döhner H, Stilgenbauer S, Pscherer A, Lichter P and Seiffert M: miRNA-130a targets ATG2B and DICER 1 to inhibit autophagy and trigger killing of chronic lymphocytic leukemia cells. Cancer Res 72: 1763-1772, 2012.

25. Borges NM, do Vale Elias M, Fook-Alves VL, Andrade TA, de Conti ML, Macedo MP, Begnami MD, Campos AH, Etto LY, Bortoluzzo AB, et al: Angiomirs expression profiling in diffuse large B-Cell lymphoma. Oncotarget 7: 4806-4816, 2016.

26. Tomonaga M: Outline and direction of revised WHO classification of tumors of haematopoietic and lymphoid tissues. Rinsho Ketsueki 50: 1401-1406, 2009.

27. Rohatiner A, d'Amore F, Coiffier B, Crowther D, Gospodarowicz M, Isaacson P, Lister TA, Norton A, Salem P, Shipp M, et al: Report on a workshop convened to discuss the pathological and staging classifications of gastrointestinal tract lymphoma. Ann. Oncol 5: 397-400, 1994.

28. Sok M, Zavrl M, Greif B and Srpčič M: Objective assessment of WHO/ECOG performance status. Support Care Cancer 27: 3793-3798, 2019

29. Ghimire P, Wu GY and Zhu L: Primary gastrointestinal lymphoma. World J. Gastroenterol 17: 697-707, 2011.

30. Chen F, Liu S, Zhou Y, Shen H and Zuo X: Mad2 overexpression is associated with high cell proliferation and reduced disease-free survival in primary gastrointestinal diffuse large B-cell lymphoma. Hematology 21: 399-403, 2016.
31. Livak KJ and Schmittgen TD: Analysis of relative gene expression data using real-time quantitative PCR and the 2(-Delta Delta C(T)) method. Methods 25: 402-408, 2001.

32. Muris JJ, Meijer CJ, Vos W, van Krieken JH, Jiwa NM, Ossenkoppele GJ and Oudejans JJ: Immunohistochemical profiling based on Bcl-2, CD10 and MUM1 expression improves risk stratification in patients with primary nodal diffuse large $B$ cell lymphoma. J Pathol 208: 714-723, 2006.

33. Hans CP, Weisenburger DD, Greiner TC, Gascoyne RD, Delabie J, Ott G, Müller-Hermelink HK, Campo E, Braziel RM, Jaffe ES, et al: Confirmation of the molecular classification of diffuse large B-cell lymphoma by immunohistochemistry using a tissue microarray. Blood 103: 275-282, 2004

34. Horn H, Ziepert M, Becher C, Barth TF, Bernd HW, Feller AC, Klapper W, Hummel M, Stein H, Hansmann ML, et al: MYC status in concert with BCL2 and BCL6 expression predicts outcome in diffuse large B-cell lymphoma. Blood 121: 2253-2263, 2013

35. Juarez-Salcedo LM, Sokol L, Chavez JC and Dalia S: Primary gastric lymphoma, epidemiology, clinical diagnosis, and treatment. Cancer Control 25: 1-12, 2018.

36. Ahmadvand M, Eskandari M, Pashaiefar H, Yaghmaie M, Manoochehrabadi S, Khakpour G, Sheikhsaran F and Montazer Zohour M: Over expression of circulating miR-155 predicts prognosis in diffuse large B-cell lymphoma. Leuk Res 70: 45-48, 2018.

37. Craig VJ, Tzankov A, Flori M, Schmid CA, Bader AG and Muller A: Systemic microRNA-34a delivery induces apoptosis and abrogates growth of diffuse large B-cell lymphoma in vivo. Leukemia 26: 2421-2424, 2012.

38. Craig VJ, Cogliatti SB, Imig J, Renner C, Neuenschwander S, Rehrauer H, Schlapbach R, Dirnhofer S, Tzankov A and Müller A: Myc-mediated repression of microRNA-34a promotes high-grade transformation of B-cell lymphoma by dysregulation of FoxP1. Blood 117: 6227-6236, 2011

39. Yang F, Miao L, Mei Y and Wu M: Retinoic acid-induced HOXA5 expression is co-regulated by HuR and miR-130a. Cell Signal 25: 1476-1485, 2013.

40. Zhou YM, Liu J and Sun W: MiR-130a overcomes gefitinib resistance by targeting met in non-small cell lung cancer cell lines. Asian Pac. J Cancer Prev 15: 1391-1406, 2014.

41. Xu N, Shen C, Luo Y, Xia L, Xue F, Xia Q and Zhang J: Upregulated miR-130a increases drug resistance by regulating RUNX3 and Wnt signaling in cisplatin-treated HCC cell. Biochem Biophys Res Commun 425: 468-472, 2012.

42. Yu X and Li Z: New insights into MicroRNAs involves in drug resistance in diffuse large B cell lymphoma. Am J Transl Res 7: 2536-2542, 2015

43. Kawamoto K, Miyoshi H, Yoshida N, Nakamura N, Ohshima K, Sone $\mathrm{H}$ and Takizawa J: MYC translocation and/or BCL 2 protein expression are associated with poor prognosis in diffuse large B-cell lymphoma. Cancer Sci 107: 853-861, 2016.

44. Plati J, Bucur O and Khosravi-Far R: Apoptotic cell signaling in cancer progression and therapy. Integr Biol 3: 279-96, 2011.

45. $\mathrm{Hu} \mathrm{S}$, Xu-Monette ZY, Tzankov A, Green T, Wu L, Balasubramanyam A, Liu WM, Visco C, Li Y, Miranda RN, et al: MYC/BCL2 protein coexpression contributes to the inferior survival of activated B-cell subtype of diffuse large B-cell lymphoma and demonstrates high-risk gene expression signatures: A report from The International DLBCL Rituximab-CHOP consortium program. Blood 121: 4021-4031, 2013.

46. Lim KH, Yang Y and Staudt LM: Pathogenetic importance and therapeutic implications of NF-kB in lymphoid malignancies. Immunol Rev 246: 359-378, 2012.

47. Feng Y,Zhou S, Li G, Hu C, Zou W, Zhang H and Sun L: Nuclear factor- $\mathrm{kB}$-dependent microRNA-130a upregulation promotes cervical cancer cell growth by targeting phosphatase and tensin homolog. Arch Biochem Biophys 598: 57-65, 2016.

48. Wang Y, Zhang X, Tang W, Lin Z, Xu L, Dong R, Li Y, Li J, Zhang Z, Li X, et al: miR-130a upregulates mTOR pathway by targeting TSC1 and is transactivated by NF- $\kappa \mathrm{B}$ in high-grade serous ovarian carcinoma. Cell Death Differ 24: 2089-2100, 2017.

49. Filip D and Mraz M: The role of MYC in the transformation and aggressiveness of 'indolent' B-cell malignancies. Leuk. Lymphoma 61: 510-524, 2019.

50. Zhu J, Zheng X and Yang X: Diagnostic and mechanistic values of microRNA-130a and microRNA-203 in patients with papillary thyroid carcinoma. J Cell Biochem 121: 3657-3666, 2020. 
51. Nguyen L, Papenhausen P and Shao H: The Role of c-MYC in B-cell lymphomas: Diagnostic and molecular aspects. Genes (Basel) 8: 116, 2017.

52. Johnson NA, Slack GW, Savage KJ, Connors JM, Ben-Neriah S, Rogic S, Scott DW, Tan KL, Steidl C, Sehn LH, et al: Concurrent expression of MYC and BCL2 in diffuse large B-cell lymphoma treated with rituximab plus cyclophosphamide, doxorubicin, vincristine, and prednisone. J Clin Oncol 30: 3452-3459, 2012

53. Lee SH, Jung YD, Choi YS and Lee YM: Targeting of RUNX3 by miR-130a and miR-495 cooperatively increases cell proliferation and tumor angiogenesis in gastric cancer cells. Oncotarget 6: 33269-33278, 2015.

54. Wang XC, Tian LL, Wu HL, Jiang XY, Du LQ, Zhang $\mathrm{H}$, Wang YY, Wu HY, Li DG, She Y, et al: Expression of miRNA-130a in nonsmall cell lung cancer. Am J Med Sci 340: 385-388, 2010

55. Zhao H, Zhang LE, Guo S, Yuan T, Xia B, Zhang L and Zhang Y: Overexpression of DNA methyltransferase 1 as a negative independent prognostic factor in primary gastrointestinal diffuse large B-cell lymphoma treated with CHOP-like regimen and rituximab. Oncol Lett 9: 2307-2312, 2015.
56. Pallasch CP, Patz M, Park YJ, Hagist S, Eggle D, Claus R, Debey-Pascher S, Schulz A, Frenzel LP, Claasen J, et al: miRNA deregulation by epigenetic silencing disrupts suppression of the oncogene PLAG1 in chronic lymphocytic leukemia. Blood 114: 3255-3264, 2009.

57. Kanagal-Shamanna R: Digital PCR: Principles and Applications. Methods Mol Biol 1392: 43-50, 2016.

58. Cao L, Cui X, Hu J, Li Z, Choi JR, Yang Q, Lin M, Ying Hui L and $\mathrm{Xu}$ F: Advances in digital polymerase chain reaction (dPCR) and its emerging biomedical applications. Biosens Bioelectron 90: 459-474, 2017.

(i) (3) This work is licensed under a Creative Commons Attribution-NonCommercial-NoDerivatives 4.0 International (CC BY-NC-ND 4.0) License. 